scientific emphasis is the trigger point ( $\operatorname{TrP})$. $\operatorname{TrP}$ is defined as hyperirritable areas within taut bands of skeletal muscle and classified as either active or latent. Although many methods have been proposed for use in the treatment of $\operatorname{TrP}$, there has been no study investigating which method is more effective.

Objectives: The aim of our study is to compare the different trigger point techniques used in the treatment of low back pain.

Methods: 28 cases with low back pain with trigger point origin were included in the study. The subjects were randomly divided into 3 groups. Strain-Counter Strain (SCS) technique was applied to Group $1(n=16)$, Integrated Neuromuscular Inhibition Technique (INIT) for Group $2(\mathrm{n}=16)$, and Ischaemic Compression Technique (ICT) for Group $3(n=16)$. The duration of treatment was a maximum of 6 weeks (12 sessions) in both three groups. Visual Analogue Scale (VAS) was used for pain severity, algometer examination was used to measure pain threshold, and Oswestry Disability Index was used to assess disability score. In addition, the Beck Depression Scale was used to assess the psychosocial status of the cases, and the STAI (State Trait Anxiety Inventory)- I and STAI-II scales were used to assess emotion-state and continuity. The evaluations were made before the treatment, after the 1st session of the treatment and at the end of the treatment (after 6 weeks). The data were analysed by using Kruskal-Wallis Test.

Results: Mean age and body mass index (BMI) of our study group were, respectively, $38.6 \pm 12.3$ years and $26.6 \pm 6.2 \mathrm{~kg} / \mathrm{m}^{2}$ in the SCS group, $34.2 \pm 10.1$ years and $26.3 \pm 5.9 \mathrm{~kg} / \mathrm{m}^{2}$ in the INIT group and $34.8 \pm 14.2$ years and $24.5 \pm 5.2 \mathrm{~kg} / \mathrm{m}^{2}$ in the ICT group. There was no significant difference among groups in respect of age, BMI, depression and anxiety score $(p>0.05)$ before the treatment. Three groups had significant decreases in pain according to the VAS and algometer $(p<0.05)$. The ROM values and function level significantly improved within three groups after treatment $(p<0.05)$. There was no statistically significant difference in pain $(p=0.13)$, lumbal flexion $(p=0.77)$, lumbal extension ROM $(p=0.43)$ and disability score $(p=0.65)$ among the three groups before and after the treatment.

Conclusions: The results indicate that patients with low back pain gain clinically benefit from trigger point tereatment on pain, ROM and function. Therefore, we suggest that physiotherapist either can apply SCS, INIT or ICT based on their clinical experience in the management of low back pain. This work was supported by Istanbul University, Scientific Research Projects (Number: TYL-2017-24209)

Disclosure of Interest: None declared

DOI: 10.1136/annrheumdis-2018-eular.1670

\section{THU0532 1 TO ASSESS WHETHER THERE IS AN ASSOCIATION BETWEEN HYPERMOBILITY AND SPORTS INJURY}

J.A. Nathan, K. Davies. Rheumatology, Brighton and Sussex University Hospitals, Brighton, UK

Background: Joint Hypermobility $(\mathrm{JH})$ is an extremely heritable condition in which joints have a range of motion beyond normal limits. This is frequently seen in healthy individuals. ${ }^{1}$ It is important to differentiate this from Joint Hypermobility Syndrome $(\mathrm{JHS}){ }^{2}$ ( $\mathrm{JH}$ is diagnosed as a Beighton score of four or more). ${ }^{3}$

Objectives: The objective of this project was to determine whether there is an association between hypermobility and sports injury.

Methods: A quantitative observational approach using a cross sectional survey was adopted. A pilot study and initial focus group was arranged, involving 10 university students. Individuals were identified as hypermobile or not using the Beighton score. All participants were asked to complete two questionnaires; the first asking demographic information; the second questionnaire was injury specific. Fisher's exact test was used for statistical analysis.

Results: A total of 114 individuals participated in the study. 62 were women and 52 men. $26 \%$ of participants were found to be hypermobile. There was no significant association between hypermobility and sports injury $(p=0.6596)$. There was a significant increase in joint and ligament sprain amongst the non-hypermobile $(\mathrm{NH})$ group covering all sports studied $(\mathrm{p}=0.0269)$. Results showed that joint dislocation was found exclusively amongst hypermobile individuals. Duration of injury in hypermobile individuals was higher then $\mathrm{NH}$. The use of oral painkillers or antiinflammatories in the semi professional group was greater then the general population.

Table 1 Prevalence of hypermobility in each sport

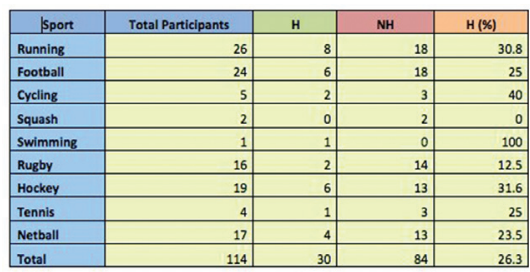

Conclusions: Hypermobility is relatively common amongst individuals and there is a lot of anecdotal evidence associating it with increased rates of injuries. This project finds that $\mathrm{NH}$ individuals are more likely to sustain a ligament or joint sprain in sports. This is thought to be due to increased joint laxity and flexibility preventing injury.

\section{REFERENCES}

[1] Simmonds JV, Keer RJ. Hypermobility and the hypermobility syndrome. Man Ther 2007;12(4):298-309.

[2] Baeza-Velasco C, Gély-Nargeot MC, Pailhez G, Vilarrasa AB. Joint hypermobility and sport: a review of advantages and disadvantages. Curr Sports Med Rep 2013;12(5):291-5.

[3] Donaldson PR. Does generalized joint hypermobility predict joint injury in sport? A review. Clin J Sport Med 2012;22(1):77-8.

Disclosure of Interest: None declared

DOI: 10.1136/annrheumdis-2018-eular.2602

\section{THU0533 PREVALENCE OF LOW BACK PAIN AND KINESIOPHOBIA IN ELDERLY RESIDENTS OF SAO PAULO CITY: A CROSS-SECTIONAL PRELIMINARY DATA}

K.E. Chang ${ }^{1}$, J.W.C. Silva ${ }^{2}$, I.M.B. Souza ${ }^{1}$, P.A. Moura ${ }^{1}$, F.J.R. França ${ }^{2}$, J. E. Pompeu ${ }^{1}$, A.P. Marques ${ }^{1} .{ }^{1}$ Department of Fonoaudiology, Physical Therapy and Occupational Therapy, Medical School at University of Sao Paulo; ${ }^{2}$ Departamento de Gerontologia Social, 2Pontifical Catholic University of Sao Paulo, Sao Paulo, Brazil

Background: Low back pain (LBP) is an important health problem around the world associated with disability, high costs for the health system and work absenteeism. A recent systematic review estimated that in Brazil, the point prevalence of LPB in the elderly is $25 \%$, superior to knee osteoarthritis and rheumatoid arthritis, being considered one of the most relevant health conditions in the elderly. Objectives: To measure the prevalence of LBP and kinesiophobia in the elderly, following the existing guidelines on conducting specific prevalence studies about LBP and to investigate the factors associated.

Methods: This is a cross-sectional study and the total sample to be recruited is 513 individuals of both genders, over 60 years old. Pain was investigated at two different times: current and last year, and pain intensity was measured by Numerical Pain Rating Scale (NPRS). Disability was measured using the Roland Morris Disability Questionnaire - Brazil version (RMDQ - BRA) and kinesiophobia was measured by the Tampa Scale for Kinesiophobia (TSK).

Results: Until now, 387 elderlies were interviewed, of which $77 \%$ were women and the mean age was $71.98( \pm 7.70)$. The prevalence of LBP was $76.23 \%$, with a punctual prevalence of $72.54 \%$ and a 12 months prevalence of $93.22 \%$. The mean NPRS score was $7.52( \pm 2.16)$, the mean RMDQ - BRA score was 11.32 $( \pm 5.35)$, and the mean of the TSK score was $43.78( \pm 7.50)$.

Conclusions: Preliminary data indicate that the prevalence of LBP and kinesiophobia are high in this population. However, the level of functional disability due is moderate. There are few studies that approach these symptoms in the elderly population, and will serve as the basis for the creation of health policies.

\section{REFERENCES:}

[1] Hoy B, Bain C, Williams G, March I, Brooks P, Blyth F, et al. A systematic review of the global prevalence of low back pain. Arthritis and Rheumatism 2012;64(6):2028-2037

[2] Manogharan S, Kongsted A, Ferreira ML, Hancock MJ. Do older adults with chronic low back pain differ from younger adults in regard to baseline characteristics and prognosis? Eur J Pain 2017;21:866-873.

[3] Leopoldino AAO, Diz JBM, Martins VT, et al. Prevalência de lombalgia na população idosa brasileira: revisão sistemática com metanálise. Rev Bras Reumatol 2016;56(3):258-269.

Disclosure of Interest: None declared DOI: 10.1136/annrheumdis-2018-eular.7081

\section{THU0534 THE EFFECT OF LUMBER STABILISATION EXERCISE ON THE BALANCE AND CLINICAL HEALTH}

K. Barut ${ }^{1}$, E. Taştaban ${ }^{2}$, F. Sendur ${ }^{2} .{ }^{1} P M R$, Aydın Devlet Hastanesi; ${ }^{2} P M R$, Adu Tip, Aydin, Turkey

Objectives: The aim of this study is to investigate the effects of lumbar stabilisation exercises on chronic low back pain in term of pain, functioning, quality of life, balance and trophic improvement of lumbar multifidus muscles. 
Methods: 66 patients with chronic low back pain were enrolled in this study. The patients were randomised and divided into two groups. Lomber stabilisation exercises, TENS and Hotpack treatments were given to the first group ( $\mathrm{n}: 28)$ while the second group ( $\mathrm{n}$ : 37 ) were treated with only TENS and Hotpack. Patients' evaluations have been carried out before and after 8 weeks following the exercises. Visuel Analogue Scale (VAS) were used to determine the pain as a numeric scale during the rest and pyhsical activity. Modified Oswestry Questionnaire Survey and Roland Morris Scale were used to evaluate of functional disability. The Short Form-36 (SF36) applied to measure of quality of life. Tetrax device has been used to evaluation the body balance. 7-15 MHZ Ultrasound has been used to evaluate the change of trophic changes of multifidus muscle's cross-sectional areas.

Results: Except falling risk, in all parameters we have observed significant improvement in group 1. Cross-sectional area of the multifidus muscles, physical role of SF-36, mental health and energy/vitality sub parameters were found significantly better in group 1 when compared to the other group. There was no significant difference between the groups when the fall index, VAS scores, Roland Morris Questionnaire and Oswestry Disability Index were considered.

Conclusions: As a result, lomber stabilisation exercises have positive effect on pain relief, improve the functional capacity and quality of life. Additionally the exercises also had benefit and increased cross-sectional areas of multifidus muscles. Disclosure of Interest: None declared

DOI: 10.1136/annrheumdis-2018-eular.1519

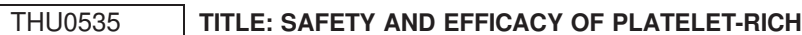 PLASMA IN TREATMENT OF CARPAL TUNNEL SYNDROME; A RANDOMISED CONTROLLED TRIAL}

L. Bagherzadeh, S.A. Raeissadat, A. Karimzadeh, M. Hashemi. Physical medicine and rehabilitation, shahid beheshti university of medical sciences, ehran, Iran, Islamic Republic of Ireland

Background: Carpal tunnel syndrome is the most common peripheral entrapment neuropathy, for which conservative treatments are the first measures taken but they are not usually sufficient.

Objectives: Recently major attention has been drawn to platelet-rich plasma, for its possible effects on axon regeneration and neurological recovery. Although few studies have evaluated the effects of this treatment in carpal tunnel syndrome, further investigations are required to reach concrete conclusion.

Methods: In this randomised controlled trial, women referring to the physical medicine and rehabilitation clinic at Shahid Modarres Hospital during 2016 with a diagnosis of mild and moderate idiopathic carpal tunnel syndrome were included and randomly assigned to two groups of control, only using a wrist splint, and platelet-rich plasma that received wrist splints along with a single local injection of platelet-rich plasma. The outcome measures were assessed via Visual Analogue Scale, the Boston Carpal Tunnel Syndrome Questionnaire and electrophysiological findings including the peak latency of sensory nerve action potential and the onset latency of the compound muscle action potential.

Results: A total of 41 women were included and randomly assigned to two groups of control (20 wrists) and platelet-rich plasma ( 21 wrists). Before treatment there were no significant differences between the two groups except for the median peak latency of sensory nerve action potential which was significantly higher among the patients in the platelet-rich plasma group $(p=0.03)$. All the measured variables significantly decreased in both groups after 10 weeks of treatment except for the median onset latency of the compound muscle action potential $(p=0.472)$. Finally, the changes in neither of the outcome measures evaluated were found to significantly differ between the two groups, even when the analyses were adjusted for age of the patients.

Conclusions: The findings of this study showed that in a relatively short period of time after treatment, a single injection of platelet-rich plasma in the wrist does not add significantly to the effects of conservative treatment with wrist splints, in regards to the women pain and symptom severity, functional status and electrophysiological parameters.

Disclosure of Interest: None declared

DOI: 10.1136/annrheumdis-2018-eular.5628

\section{THU0536 \\ KNOWLEDGE OF AND EXPECTATIONS ABOUT FUNCTIONAL RESTORATION PROGRAM FOR CHRONIC LOW BACK PAIN ARE OFTEN FALSE: A MIRROR} SURVEY OF 40 PATIENTS AND 59 PHYSICIANS IN 2017

L. Pierre $^{1}$, F. Bailly ${ }^{1}$, M. Assadourian ${ }^{1}$, V. Foltz ${ }^{1}$, A. Potel ${ }^{1}$, L. Morardet ${ }^{1}$, S. Ascione ${ }^{1}$, M. Le Ralle ${ }^{1}$, A. Dupeyron ${ }^{2}$, N. Ibrahim ${ }^{3}$, I. Griffoul-Espitalier ${ }^{4}$ B. Duplan ${ }^{5}$, J. Beaudreuil ${ }^{6}$, B. Fautrel ${ }^{1}$, L. Gossec ${ }^{1}$. ${ }^{1}$ Sorbonne university; ${ }^{2}$ Nimes hospital; ${ }^{3}$ Orleans hospital; ${ }^{4}$ Tours hospital; ${ }^{5}$ Metropole Savoie hospital;

${ }^{6}$ Lariboisiere hospital, Paris, France

Background: Functional restoration programs (FRP) are multi-disciplinary programs that have demonstrated their effectiveness in chronic low back pain (CLBP) but they appear to be little known by patients and/or physicians.

Objectives: To assess the knowledge and expectations of CLBP patients and physicians about FRP.

Methods: Multicenter cross-sectional study in 2017 in 6 tertiary-care hospitals in France. Consecutive patients with CLBP (more than 6 weeks) who were seen for their CLBP were included. Physicians (rheumatologists or general practitioners, GPs) who had referred at least 5 patients to the tertiary-care centres were sent a survey. Patients and physicians were asked about their knowledge and expectations of a FRP. Results were scored as 'correct' regarding health professionals involved in the FRP, if both doctors and (physiotherapists or physical activity coach) were ticked; and 'correct' for duration if 3 to 6 weeks. Expectations regarding the FRP were rated on a list of potential expectations on a scale of $0-10$. Expectations were scored ' correct' if return to work was scored $\geq 7 / 10$, and 'fully correct' if physical activity and pain management, but not 'healing' were also expected. Responses were then compared between patients and physicians by Chi 2 test.

Results: Of 172 patients, median age 48 years (IQR 38-58), median CLBP duration 5 years (IQR 2-10), 60.0\% women: 110 (64.0\%) had no knowledge of FRP 22 had already participated in an FRP. The remaining 40 patients were compared to physicians (figure 1). Of 80 physicians, $42.5 \%$ GPs and $53.7 \%$ rheumatologists, $57.5 \%$ women: 21 (26.2\%) had no knowledge of FRP ( $p$ value $<0.0001$ vs patients). The remaining 59 were compared to the 40 patients.

Knowledge of FRP health professionals was 'correct' for $13 / 40$ (32.5\%) patients vs $41 / 59(69.5 \%)$ physicians ( $p=0.0003)$; and knowledge of duration was 'correct' for $26 / 40(65.0 \%)$ vs $46 / 59(78.0 \%)$ physicians ( $p=0.15)$.

Expectations were 'correct' for $21 / 40(52.5 \%)$ patients vs $44 / 59(74.6 \%)$ for physicians $(p=0.02)$, and 'fully correct' for $9 / 40(22.5 \%)$ patients vs $16 / 59(27.1 \%)$ for physicians $(p=0.6)$.

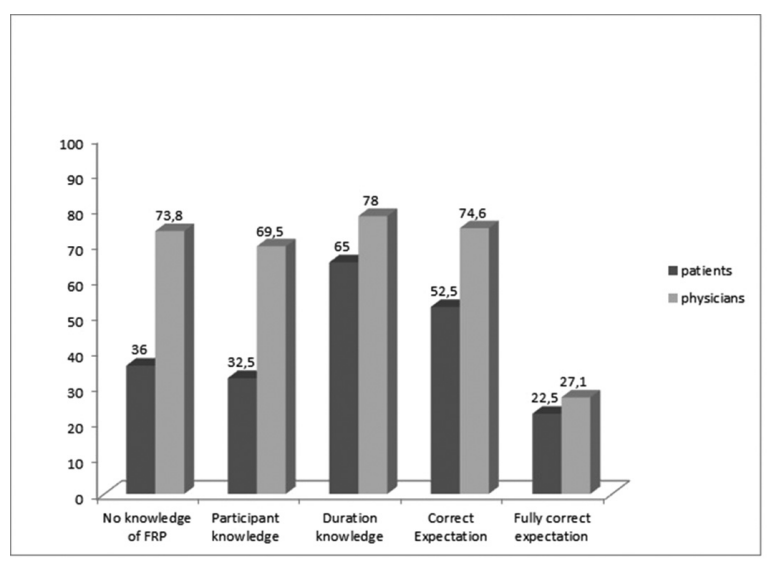

Conclusions: FRP was largely unknown to patients with CLBP. Even those who were aware of the FRP did not know what to expect. While physicians' knowledge and perception of the FRP was better, there was still a lack of knowledge and therefore a likely underutilization or misuse of the FRP. Information campaigns are needed.

Disclosure of Interest: None declared

DOI: 10.1136/annrheumdis-2018-eular.3754 